\title{
LARGE GENETIC DIFFERENTIATION AND LOW VARIATION IN VECTOR COMPETENCE FOR DENGUE AND YELLOW FEVER VIRUSES OF AEDES ALBOPICTUS FROM BRAZIL, THE UNITED STATES, AND THE CAYMAN ISLANDS
}

\author{
RICARDO LOURENÇO DE OLIVEIRA, MARIE VAZEILLE, ANA MARIA BISPO DE FILIPPIS, AND \\ ANNA-BELLA FAILLOUX \\ Laboratórios de Transmissores de Hematozoários e de Flavivírus, Instituto Oswaldo Cruz, Rio de Janeiro, Brazil; Unité d'Ecologie \\ des Systèmes Vectoriels, Institut Pasteur, Paris, France
}

\begin{abstract}
We conducted a population genetic analysis of Aedes albopictus collected from 20 sites in Brazil, the United States (Florida, Georgia, and Illinois), and the Cayman Islands. Using isoenzyme analysis, we examined genetic diversity and patterns of gene flow. High genetic differentiation was found among Brazilian samples, and between them and North American samples. Regression analysis of genetic differentiation according to geographic distances indicated that $A$ e. albopictus samples from Florida were genetically isolated by distance. Infection rates with dengue and yellow fever viruses showed greater differences between two Brazilian samples than between the two North American samples or between a Brazilian sample and a North American sample. Introductions and establishments of new Ae. albopictus populations in the Americas are still in progress, shaping population genetic composition and potentially modifying both dengue and yellow fever transmission patterns.
\end{abstract}

\section{INTRODUCTION}

Aedes albopictus is a mosquito species native to Southeast Asia $^{1}$ with a wide distribution in the Oriental region, including New Guinea, most islands in the Indian Ocean, and some islands in the Pacific region such as Hawaii and Guam. ${ }^{2}$ The distribution of Ae. albopictus has expanded recently in the Americas; it was established in Houston, Texas in $1985,{ }^{3}$ probably arriving in shipments of used tires from Japan. ${ }^{4}$ Soon afterwards. South America was infested by Ae. albopictus; in 1986, it was detected in southeastern Brazil. ${ }^{5}$ Infestations in Brazil seemed to have originated from tropical Asia. ${ }^{4}$ This species is now established in 23 states in the United States ${ }^{6}$ and in 22 states in Brazil (Brazilian Ministry of Health, unpublished data). Aedes albopictus is frequent found in the southeastern and southern states of Brazil, but its pattern of distribution is scattered in coastal northeastern and central Brazil; it is essentially absent in the Amazon region and in the inland dry areas of northeastern Brazil.

In regions where the distribution of Ae. albopictus and Ae. aegypti overlap, species segregation has shown that $A e$. aegypti predominate in urban zones with high concentration of humans, while Ae. albopictus predominates in periphery of cities and semi-rural localities (Braks $\mathrm{M}$ and others, unpublished data). The colonization history of Ae. albopictus can be compared with that of $A e$. aegypti, which originated from Africa. ${ }^{7}$ Both species have spread worldwide because of their ability to breed in human-made containers. ${ }^{8}$ Unlike $A e$. aegypti, Ae. albopictus has developed a photoperiodic egg diapause and freezing tolerance, ${ }^{4}$ allowing colonization in temperate zones. In the Americas, the introduction of Ae. albopictus has been associated with a decrease in the abundance of Ae. aegypti. ${ }^{9,10}$ For example, in Texas, Ae. albopictus is three times more abundant than $A e$. aegypti, ${ }^{3}$ but the distribution of native mosquitoes such as Ae. triseriatus, a treehole mosquito, is not affected. ${ }^{11}$ However, in Southeast Asia, Ae. aegypti has displaced Ae. albopictus. ${ }^{12}$ Typically, Ae. albopictus prefers suburban and rural areas where it breeds in natural containers such as tree holes, leaf axils, bamboo internodes, and artificial containers such as tin cans and tires. ${ }^{13}$

In the Americas, control programs for the eradication of urban yellow fever, which were initiated in 1916 by the
Rockefeller Foundation, and then continued by the Pan American Health Organization from 1940 to 1950, led to the disappearance of Ae. aegypti from several countries in the late 1960s. ${ }^{14}$ Urban yellow fever has not been reported from the Americas since $1954 .{ }^{15}$ However, jungle yellow fever, which is transmitted by sylvan mosquitoes, e.g., Haemagogus janthinomys, has increased in Bolivia, Brazil, Columbia, Ecuador, and Peru. ${ }^{16}$ After the relaxation of the control program in the early 1970s, Ae. aegypti has re-infested most American countries, ${ }^{17}$ colonizing more areas than before the eradication campaign. ${ }^{18}$ Thus, reinvasions by Ae. aegypti of cities pose the threat of re-urbanization of yellow fever. ${ }^{19,20}$

Dengue became a serious public health problem in the Americas in 1981 with an outbreak in Cuba caused by the dengue type 2 virus serotype, and resulted in 340,000 cases and 158 deaths, mostly due to dengue hemorrhagic fever (DHF) ${ }^{21}$ Since then, many countries in the Americas have become endemic regions for dengue, with sporadic cases of DHF generally related to Ae. aegypti. ${ }^{22}$ The introduction and establishment of Ae. albopictus in the United States and Brazil has potentially serious medical implications because it is also a vector of dengue ${ }^{1}$ and other arboviruses. ${ }^{23}$ Aedes albopictus has been incriminated as a dengue vector in Japan, Indonesia, the Seychelles, Thailand, Malaysia, ${ }^{13}$ and more recently in 2001 in Hawaii (Reiter P, unpublished data). In the continental Americas, Ae. albopictus has never been implicated in a dengue epidemic, ${ }^{24}$ but it has been found naturally infected with dengue virus in Mexico ${ }^{24}$ and Brazil. ${ }^{25}$ Because of its lack of ecologic specialization, it is suspected to be involved in the transfer of enzootic forest viruses into inhabited areas in Southeast Asia. ${ }^{26}$ Thus, it has been assumed that Ae. albopictus could introduce urban yellow fever in South America by linking the sylvatic habitat occupied by the Haemagogus spp. mosquitoes with the urban environment occupied by Ae. aegypti. ${ }^{27}$

Aedes albopictus in North America has been shown to be an efficient experimental vector of dengue viruses ${ }^{28,29}$ and yellow fever virus. ${ }^{28}$ In this study, we addressed the following questions: 1) do Brazilian populations of Ae. albopictus carry yellow fever and dengue viruses as efficiently as North American populations, 2) are Brazilian mosquito populations 
genetically differentiated from North American populations, and 3) what are the implications of our findings for transmission of dengue and yellow fever?

\section{MATERIALS AND METHODS}

Mosquito samples. Aedes albopictus were collected from 10 sites in Brazil, 9 sites in the United States, and 1 site in the Cayman Islands (Table 1 and Figure 1). In Brazil, Ae. albopictus was intentionally sampled from localities in its northern (São Luís [SAO]) and southern (Três Passos [RGS]) regions, where the climate, range of temperature, and biotope type vary considerably. We chose sites with variable urbanization levels and human densities, i.e., from rural or semi-urban areas with a preserved natural environment and low human densities (Represa do Cigano [RCI], Tinguá [TIN], and RGS), urban centers with medium (Moquetá [MOQ] and Paranaguá [PAR]) and high (SAO, Salvador [SAL], and Florianópolis [FLO]) human densities, and a slum (Comandados Soares [CSO]) with a lack of urban services and very high human density and environmental degradation. Mosquitoes from Brazil were sampled in March-April 2001 using around 20 ovitraps containing $10 \%$ hay infusion in tap water ${ }^{30}$ per locality. Mosquitoes from North America were collected in 2000-2001 and composed of larvae and adults, except for the sample from Vero Beach (VER), where collections were also made with ovitraps. ${ }^{30}$ Samples were reared to obtain adults $\left(F_{0}\right.$ generation for all samples and $F_{1}$ for the West Palm Beach [WPB] North American sample), which were fed on mice to obtain eggs $\left(\mathrm{F}_{1} / \mathrm{F}_{2}\right.$ generation $)$. The $\mathrm{F}_{0} / \mathrm{F}_{1}$ adults were kept at $-80^{\circ} \mathrm{C}$ until use and when possible, $\mathrm{F}_{1} / \mathrm{F}_{2}$ females were infected with dengue 2 virus and yellow fever virus (see Table 1 for more details).

Isolation of virus. The Bangkok strain of dengue type 2, provided by Dr. Leon Rosen (Institut Pasteur, Paris, France), was isolated in 1974 from a serum sample of a DHF patient from Bangkok, Thailand. ${ }^{31}$ This virus had been passed only in mosquito species by intrathoracic inoculation: two passages in Ae. albopictus and two passages in Toxorhynchites amboinensis. Our dengue 2 virus stocks were prepared on Ae. albopictus $\mathrm{C6} / 36$ cells. We used a final titer of $10^{8.2} \mathrm{MID}_{50}(50 \%$ mosquito infectious dose for $A e$. aegypti)/mL for mosquito infections.

The yellow fever virus strain (FIOCRUZ 74018/MG/01) was isolated on C6/36 cells in 2001 from the serum of a 39year-old fatal human case of yellow fever from Bom Despacho in the State of Minas Gerais in Brazil. ${ }^{32}$ The titer used in the infectious meal was $10^{8.7} \mathrm{MID}_{50} / \mathrm{mL}$.

Experimental infection of $F_{1}$ females and statistical analysis. For experimental infection with dengue type 2 virus, we performed one or two assays per sample depending on the number of available females. For mosquito infections with yellow fever virus, only one assay was carried out for each sample. Five to ten days after emergence, females were deprived of sucrose solution 24 hours before exposure to virus. The infectious meal contained two-thirds washed rabbit erythrocytes, one-third virus suspension, and $5 \times 10^{-3} \mathrm{M}$ ATP. After 20 minutes of feeding, fully engorged females were kept at $28^{\circ} \mathrm{C}$ for 14 days. To detect infected females (i.e., with dengue or yellow fever viruses in nervous tissues), we used an indirect immunofluorescence assay on head squashes. ${ }^{33}$ Viral infection was also tested in the Paea colony of Ae. aegypti (collected in 1994 in Tahiti, French Polynesia), whose infection rate for dengue virus is known. ${ }^{34}$

We conducted analysis to compare infection rates (i.e., the proportion of females becoming infected by dengue and yellow fever viruses 14 days after infection). Independence of rows and columns in an $\mathrm{R} \times \mathrm{C}$ contingency table was tested using Fisher's exact test. ${ }^{35}$

TABLE 1

Aedes albopictus collected in Brazil, the Cayman Islands, and the United States in 2000-2001*

\begin{tabular}{|c|c|c|c|c|c|c|c|}
\hline \multirow[b]{2}{*}{ No. } & \multirow[b]{2}{*}{ Sample } & \multirow[b]{2}{*}{ City } & \multirow[b]{2}{*}{ State or country } & \multirow[b]{2}{*}{$\begin{array}{l}\text { Date of } \\
\text { collection }\end{array}$} & \multirow[b]{2}{*}{$\begin{array}{l}\text { Number of } \\
\mathrm{F}_{0} \text { adults }\end{array}$} & \multicolumn{2}{|c|}{ Generation tested } \\
\hline & & & & & & $\begin{array}{l}\text { Experimental } \\
\text { infection }\end{array}$ & $\begin{array}{l}\text { Isoenzyme } \\
\text { analysis }\end{array}$ \\
\hline \multicolumn{8}{|l|}{ Brazil } \\
\hline 1 & CAR & Cariacica & Espírito Santo & May 2001 & 69 & $\mathrm{~F}_{1}$ & $\mathrm{~F}_{0}$ \\
\hline 2 & $\mathrm{CSO}$ & Comandados Soares & Rio de Janeiro & Mar 2001 & 54 & $\mathrm{~F}_{1}$ & $F_{0}$ \\
\hline 3 & FLO & Florianópolis & Santa Cantarina & May 2001 & 108 & $\mathrm{~F}_{1}$ & $\mathrm{~F}_{0}$ \\
\hline 4 & MOQ & Moquetá & Rio de Janeiro & Mar 2001 & 91 & $\mathrm{~F}_{1}$ & $\mathrm{~F}_{0}$ \\
\hline 5 & PAR & Paranaguá & Paraná & May 2001 & 840 & $F_{1}$ & $\mathrm{~F}_{0}$ \\
\hline 6 & RCI & Represa do Cigano & Rio de Janeiro & Apr 2001 & 828 & $\mathrm{~F}_{1}$ & $\mathrm{~F}_{0}$ \\
\hline 7 & RGS & Trềs Passos & Rio Grande do Sul & May 2001 & 27 & $F_{1}$ & $\mathrm{~F}_{0}$ \\
\hline 8 & SAL & Salvador & Bahia & Apr 2001 & 228 & $\mathrm{~F}_{1}$ & $\mathrm{~F}_{0}$ \\
\hline 9 & SAO & São Luís & Maranhão & Apr 2001 & 33 & $F_{1}$ & $\mathrm{~F}_{0}$ \\
\hline 10 & TIN & Tinguá & Rio de Janeiro & Apr 2001 & 1,575 & $\mathrm{~F}_{1}$ & $\mathrm{~F}_{0}$ \\
\hline \multicolumn{8}{|c|}{ Caribbean } \\
\hline 11 & CAY & Georgetown & Cayman Islands & Aug 2000 & 26 & - & $\mathrm{F}_{0}$ \\
\hline \multicolumn{8}{|c|}{ United States } \\
\hline 12 & COT & Cottondale & Florida & Jan 2001 & 20 & - & $\mathrm{F}_{0}$ \\
\hline 13 & HIA & Hiawassee & Georgia & Oct 2000 & 20 & - & $\mathrm{F}_{0}$ \\
\hline 14 & JAC & Jacksonville & Florida & Jan 2001 & 20 & - & $F_{0}$ \\
\hline 15 & $\mathrm{KRO}$ & Miami & Florida & Oct 2000 & 20 & - & $\mathrm{F}_{0}$ \\
\hline 16 & NOR & Norcross & Georgia & Oct 2000 & 19 & - & $F_{0}$ \\
\hline 17 & PAH & Pahokee & Florida & Sep 1999-Oct 2001 & 513 & - & $\mathrm{F}_{0}$ \\
\hline 18 & STL & East Saint Louis & Illinois & Oct 2000 & 22 & - & $\mathrm{F}_{0}$ \\
\hline 19 & VER & Vero Beach & Florida & Sep 2001 & 345 & $\mathrm{~F}_{1}$ & $\mathrm{~F}_{0}$ \\
\hline 20 & WPB & West Palm Beach & Florida & Sep 2001 & 850 & $\mathrm{~F}_{2}$ & $\mathrm{~F}_{1}$ \\
\hline
\end{tabular}



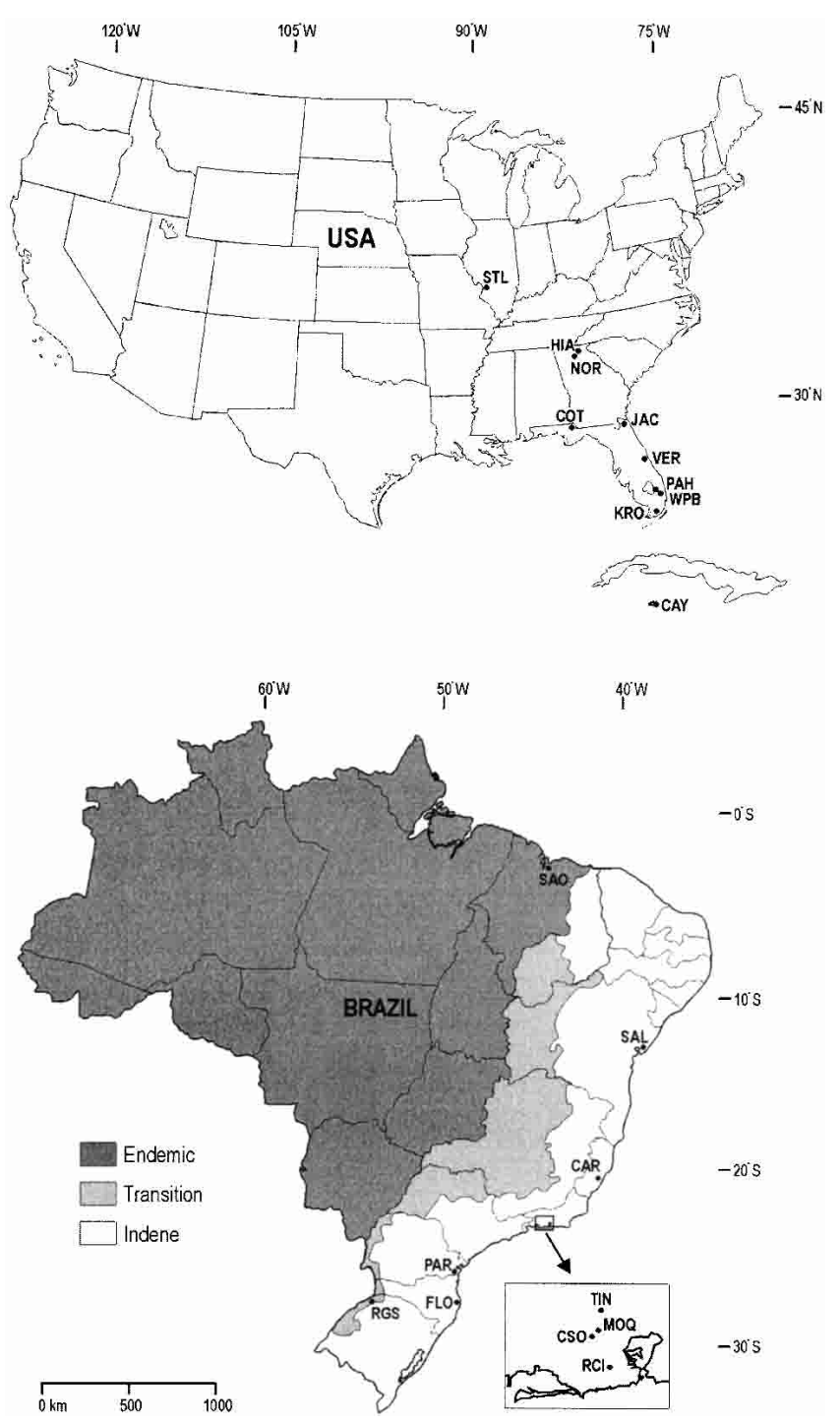

Figure 1. Location of Aedes albopictus sampled in 2000-2001 in the United States, the Cayman Islands, and Brazil. STL = East Saint Louis; HIA $=$ Hiawassee; NOR $=$ Norcross; COT $=$ Cottondale; JAC $=$ Jacksonville; VER $=$ Vero Beach; PAH = Pahokee; WPB $=$ West Palm Beach; KRO = Miami; CAY = Georgetown; $\mathrm{SAO}=$ São Luís; SAL $=$ Salvador; CAR $=$ Cariacica; TIN $=$ Tinguá; MOQ $=$ Moquetá; $\mathrm{CSO}=$ Comandados Soares; RCI = Represa do Cigano; PAR = Paranaguá; FLO = Florianópolis; RGS = Três Passos; Indene $=$ a zone with no circulation of yellow fever virus.

Isoenzyme electrophoresis and genetic analysis. Each mosquito was ground in $25 \mu \mathrm{L}$ of distilled water and after a lowspeed centrifugation, the supernatant containing the soluble proteins was loaded onto a $12.8 \%$ starch gel in Tris-maleateEDTA (pH 7.4) buffer and subjected to electrophoresis for 4-5 hours. The most polymorphic loci encoding enzymes were chosen: glutamate oxaloacetate transaminases (Got-1 and Got-2), glycerol-3-phosphate dehydrogenase (Gpd), hexokinases (Hk-1 and Hk-2), malate dehydrogenase (Mdh), malic enzyme (Me), phosphoglucoisomerase (Pgi), and phosphoglucomutase (Pgm).

For genetic analysis, the GENEPOP software (version 3.1) developed by Raymond and Rousset ${ }^{35}$ was used. Departure from Hardy-Weinberg equilibrium was measured using the $\mathrm{F}_{\mathrm{IS}}{ }^{36}$ and tested using an exact test procedure. ${ }^{37}$ For each sample, linkage disequilibrium between pairs of loci was tested using Fisher's test on $\mathrm{R} \times \mathrm{C}$ contingency tables. Genetic differentiation was measured using the $\mathrm{F}_{\mathrm{ST}}{ }^{36}$ Isolation by geographic distance ${ }^{38}$ was tested by estimating rank correlations between $\mathrm{F}_{\mathrm{ST}} /\left(1-\mathrm{F}_{\mathrm{ST}}\right)$ calculated between pairs of samples and Ln distances.

\section{RESULTS}

Infection rates for dengue type 2 virus. The infection rates for dengue type 2 virus in 12 Ae. albopictus samples ranged from $22.5 \%$ (CSO replicate a) to $80.0 \%$ (RGS replicate a) (Table 2). When infection rates between control replicates were compared, two significant differences were found in the CSO $(P=0.006)$ and TIN replicates $(P=0.043)$. Replicates $\mathrm{b}$ of CSO and TIN were not considered for further analysis because they corresponded to assays with the lowest infection rates obtained in the controls. When infection rates were compared with the corresponding control, only one sample was not significantly different (PAR replicate a; $P=0.087$ ). The SAO sample showed a significant difference $(P<0.05)$ between replicates. When samples were grouped according to country, a significant difference was detected among samples collected in Brazil $(P<0.0001)$, whereas two samples from the United States were not significantly different $(P=0.355)$. The two samples from the United States (VER and WPB) showed infections rates similar to those of Cariacica (CAR) replicate a and SAO replicate $b$.

When grouping was analyzed according to climate/biotope type and human population densities, significant differences $(P<0.05)$ was obtained for all categories except for the two samples collected in the rural outskirts of Rio de Janeiro (RCI and TIN; $P=0.5217$ ). Plotting geographic distances

TABLE 2

Infection rates of Aedes albopictus with dengue-2 virus*

\begin{tabular}{lcccc}
\hline & & \multicolumn{2}{c}{$\%$ infected females (n) } & \\
\cline { 3 - 4 } Sample & Replicate & Assay & Control & $P^{\dagger}$ \\
\hline Brazil & & & & \\
CAR & a & $47.02(151)$ & $98.21(56)$ & $<\mathbf{0 . 0 0 0 1}$ \\
CSO & a & $22.5(40)$ & $98.55(69)$ & $<\mathbf{0 . 0 0 0 1}$ \\
FLO & a & $67.86(56)$ & $100(56)$ & $<\mathbf{0 . 0 0 0 1}$ \\
& b & $56.06(66)$ & $100(54)$ & $<\mathbf{0 . 0 0 0 1}$ \\
$P^{\dagger}$ & & 0.195 & 1.0 & \\
MOQ & a & $68.42(57)$ & $96.82(63)$ & $\mathbf{0 . 0 0 0 1}$ \\
& b & $50.0(60)$ & $90.0(70)$ & $<\mathbf{0 . 0 0 0 1}$ \\
$P^{\dagger}$ & & 0.060 & 0.172 & \\
PAR & a & $72.90(107)$ & $85.0(60)$ & 0.087 \\
RCI & a & $71.14(149)$ & $96.67(60)$ & $<\mathbf{0 . 0 0 0 1}$ \\
RGS & a & $80.0(75)$ & $100(56)$ & $\mathbf{0 . 0 0 0 1}$ \\
& b & $75.0(36)$ & $100(54)$ & $\mathbf{0 . 0 0 0 1}$ \\
$P^{\dagger}$ & & 0.625 & 1.0 & \\
SAL & a & $31.09(119)$ & $93.33(45)$ & $<\mathbf{0 . 0 0 0 1}$ \\
SAO & a & $63.08(65)$ & $100(56)$ & $<\mathbf{0 . 0 0 0 1}$ \\
& b & $41.67(72)$ & $100(54)$ & $<\mathbf{0 . 0 0 0 1}$ \\
$P_{\dagger}^{\dagger}$ & & $\mathbf{0 . 0 1 5}$ & 1.0 & \\
TIN & a & $66.18(68)$ & $98.11(53)$ & $<\mathbf{0 . 0 0 0 1}$ \\
$P \dagger$ & & $<\mathbf{0 . 0 0 0 1}$ & & \\
United States & & & & \\
VER & a & $38.6(127)$ & $85.2(115)$ & $<\mathbf{0 . 0 0 0 1}$ \\
WPB & a & $44.6(112)$ & $85.0(60)$ & $<\mathbf{0 . 0 0 0 1}$ \\
$P^{\dagger}$ & & 0.355 & & \\
\hline
\end{tabular}

$* \mathrm{n}=$ number of females tested. The mosquito control is the Ae. aegypti Paea strain from Tahiti in French Polynesia. For definitions of samples, see Table 1.

$\dagger$ Probability of homogeneity by Fisher's exact test. Significant values $(P<0.05)$ are in bold. 
separating samples against probabilities of homogeneity calculated when the corresponding infection rates were compared showed that 53 of 66 comparisons were highly significant $(P<0.05)$, among which 36 corresponded to comparisons between Brazilian samples (Figure 2).

Infection rates for yellow fever virus. The infection rates for yellow fever virus in 12 Ae. albopictus samples ranged from $3.48 \%$ (SAO) to $30.95 \%$ (RGS) (Table 3 ). The VER sample the United States showed a rate similar to those of CSO and TIN, and the rate for WPB was similar to those of PAR and SAL. When samples were compared within a country, a significant difference $(P<0.05)$ was demonstrated among the 10 Brazilian samples $(P<0.0001)$, whereas two North American samples were similar $(P=0.171)$.

When grouping was done according to climatic characteristics, significant differences $(P<0.05)$ were found, whereas when groupings were analyzed according to human population densities, all infection rates were similar $(P>0.05)$, except for the RGS sampled $(P=0.0002)$. When geographic distances were analyzed according to probabilities of homogeneity estimated when comparing infection rates, 25 of 66 comparisons were highly significant $(P<0.05)$, mostly corresponding to comparisons between Brazilian samples (i.e., 20 of 25 tests) (Figure 2).

Population differentiation. When testing Hardy-Weinberg equilibrium, we conducted 91 tests and the results of 29 were significant $(P<0.05)$. Eighteen tests showed a heterozygote excess and nine tests showed a heterozygote deficit. When Hk-1 and Hk-2 were removed from the data set, only 10 test results remained significant $(P<0.05)$, with eight showing a heterozygote deficit (Cottondale [COT]/Got-2, Jacksonville [JAC]/Got-2, Miami [KRO]/Got-2, Norcross [NOR]/Got-2,
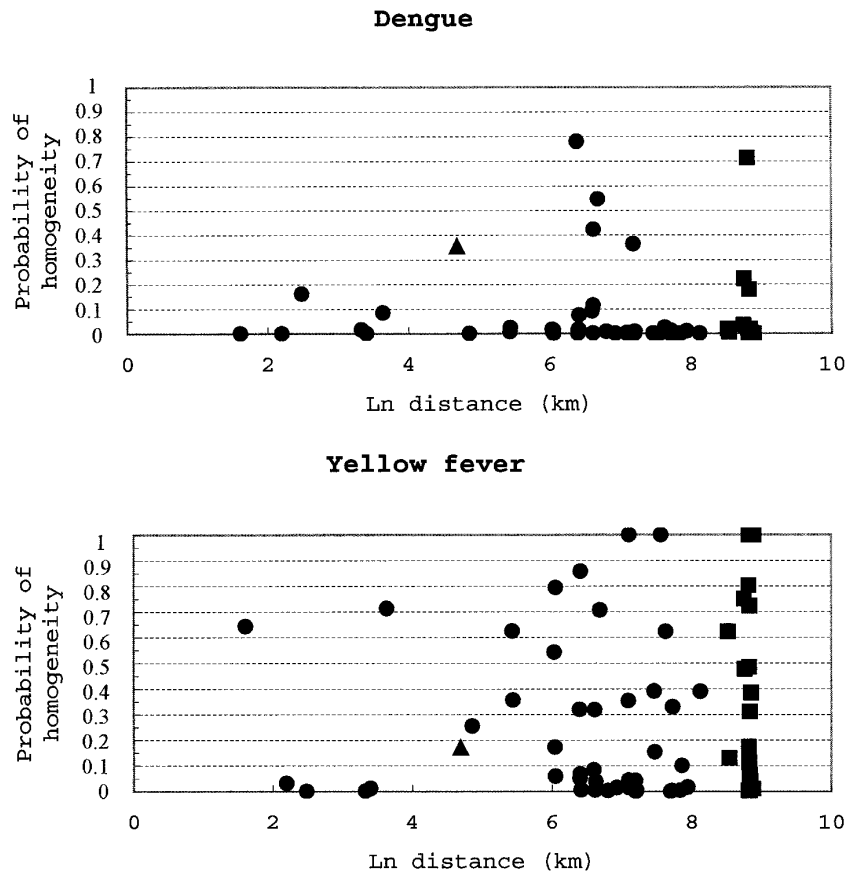

FIGURE 2. Geographic distances separating pairs of Aedes albopictus samples plotted against the probability of homogeneity between infection rates tested using Fisher's exact test. Dots correspond to comparisons between two Brazilian samples, squares to comparisons between one Brazilian sample and one North American sample, and triangles to comparisons between two North American samples.
TABLE 3

Infection rates of Aedes albopictus with yellow fever virus*

\begin{tabular}{|c|c|c|}
\hline \multirow[b]{2}{*}{ Sample } & \multicolumn{2}{|c|}{$\%$ infected females (n) } \\
\hline & Assay & Control \\
\hline \multicolumn{3}{|l|}{ Brazil } \\
\hline SAO & $3.48(115)$ & $50.0(60)$ \\
\hline SAL & $18.42(114)$ & $55.93(59)$ \\
\hline CAR & $6.30(127)$ & $49.15(59)$ \\
\hline $\mathrm{CSO}$ & $13.51(37)$ & $43.33(60)$ \\
\hline MOQ & $16.67(96)$ & $44.07(59)$ \\
\hline RCI & $7.5(120)$ & $48.33(31)$ \\
\hline TIN & $14.28(119)$ & $60.53(38)$ \\
\hline PAR & $19.01(121)$ & $56.14(57)$ \\
\hline FLO & $9.65(114)$ & $41.67(60)$ \\
\hline RGS & $30.95(84)$ & $29.81(104)$ \\
\hline$P \dagger$ & $<0.0001$ & \\
\hline \multicolumn{3}{|c|}{ United States } \\
\hline VER & $14.2(134)$ & $49.1(116)$ \\
\hline WPB & $21.4(112)$ & $56.1(97)$ \\
\hline$P \dagger$ & 0.171 & \\
\hline
\end{tabular}

CAR/Me, FLO/Me, Hiawassee [HIA]/Me, and East Saint Louis $[\mathrm{STL}] / \mathrm{Me})$ and two showing a heterozygote excess (CAR/Pgm and Pahokee [PAH]/Pgm) (Appendix 1). Genotypic associations between pairs of loci were also tested. Among 142 combinations of loci, only one (Pgi-Mdh at PAR) remained significant when the Bonferroni sequential test was taken into account. According to Ohta, ${ }^{39}$ this result was due to genetic drift rather than selection.

When genetic divergence among all 20 samples was examined, a high and significant differentiation was detected $\left(\mathrm{F}_{\mathrm{ST}}\right.$ $=+0.249, P<0.0001)$. Brazilian samples were highly differentiated $\left(\mathrm{F}_{\mathrm{ST}}=+0.136\right)$, although less differentiated than North American samples $\left(\mathrm{F}_{\mathrm{ST}}=+0.289\right)$. When the relationship between $\mathrm{F}_{\mathrm{ST}} /\left(1-\mathrm{F}_{\mathrm{ST}}\right)$ and $\mathrm{Ln}$ distance was estimated, the correlation was positive $(\mathrm{b}=+0.039)$ and significant $(P=$ 0.002 ), indicating a slight tendency to an increase in genetic differentiation with geographic distances (Figure 3). This was more easily detected for small distances (within 1,000 km), as among the five samples collected in Florida. An isolation by distance was observed for samples collected along the Florida peninsula (JAC, KRO, PAH, VER, and WPB) $(\mathrm{b}=+0.633$, $P=0.018)$.

\section{DISCUSSION}

We showed that differences in infections rates for both dengue and yellow fever viruses were greater between Brazilian populations of $A$ e. albopictus than between a Brazilian and North American populations. In addition, based on our samples, Brazilian populations tended to be more differentiated than North American samples. Evidence of isolation by distance was detected among samples collected along the Florida peninsula, which showed that species tend to less dispersal using human modes of transportation such as roads.

Aedes albopictus has been incriminated as a vector of dengue in several regions. ${ }^{2}$ Many suspected cases of dengue have been imported into the United States. However, the first dengue outbreak due to Ae. aegypti occurred in Texas in $1980 .{ }^{40}$ In Brazil, dengue outbreaks have been associated with $A e$. 
All samples $(\mathrm{N}=20)$
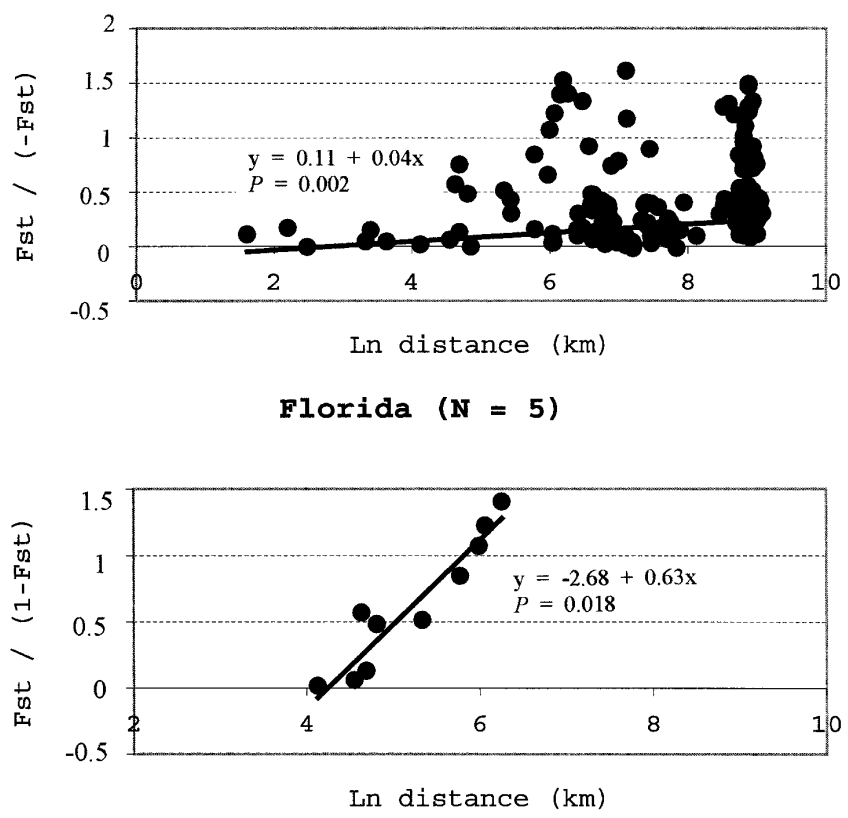

FiguRE 3. Genetic differentiation of Aedes albopictus in Brazil, the United States, and the Cayman Islands according to geographic distances separating samples.

aegypti, and the role of Ae. albopictus in virus transmission in nature remains to be confirmed. ${ }^{41}$ However, dengue viruses have been isolated from larvae of Ae. albopictus. ${ }^{25}$ Urban yellow fever has not been reported from the Americas since 1954, except for a small outbreak recently reported in Santa Cruz, Bolivia. ${ }^{19}$ However, the high infestation index of $A e$. aegypti in cities and the recent introduction of Ae. albopictus increase the threat of urbanization of yellow fever transmission in South America. ${ }^{32}$ Our results showed that Brazilian Ae. albopictus were as efficient as North American populations in being infected with dengue and yellow fever viruses. Using the same titer of dengue virus type 2 in the infectious meal, we observed infected rates that were lower than those estimated by Mitchell and others, ${ }^{28}$ who used $\mathrm{F}_{2} / \mathrm{F}_{3}$ generations of a the Houston strain established from 48 females. It has been demonstrated that infection rates tend to increase with the number of laboratory generations of mosquitoes. ${ }^{42,43}$ Using a different method of virus titration and a colony of $A e$. albopictus from Cariacica, Brazil, Miller and Ballinger ${ }^{44}$ demonstrated a lower infection rate for dengue virus type $2(38 \%)$ and higher rates for yellow fever virus (36-57\%) than we found using $F_{1}$ females from the same locality $(47.0 \%$ and $6.3 \%$, respectively). In addition, studies using a lower virus titer $\left(10^{6} \mathrm{MID}_{50}\right)$ and a long-term laboratory colony of $\mathrm{Ae}$. albopictus from Rio de Janeiro found lower infection rates for dengue virus (35.9-48\%) (Castro $\mathrm{M}$ and others, unpublished data). These results highlight the importance of using the same experimental conditions (generation of mosquito used, incubation period, virus titer, passage history of the viral strain) when comparing infection rates. Moreover, laboratory-colonized strains of Ae. aegypti, such as the Paea strain, when used as controls were chosen based on their homogenous infection rates. This has been confirmed for a dengue virus infection, ${ }^{34}$ but is more difficult to obtain for a yellow fever virus YF infection. ${ }^{45}$
In addition, differences in infection rates were greater between two Brazilian samples than between some Brazilian samples and the two North American samples tested. Based on our results, we can assume that as successive introductions of Ae. albopictus populations continue to occur in other geographic regions (likely through used tire imports), established mosquito populations will undergo genetic changes that may alter vector competence.

Brazilian as well as North American populations of $A e$. albopictus were highly differentiated, even those that were geographically close to each other (e.g., in Rio de Janeiro, 5-38 km apart). Samples of Ae. albopictus were more differentiated within a city than those collected on a larger geographic scale. This pattern was also observed using a random amplified polymorphic DNA technique, which showed the high genetic variation observed in local Brazilian populations. ${ }^{46}$ One explanation could be that drastic reductions occurred in founding populations that are likely due to insecticide treatments. ${ }^{47}$ Over distances of $90-250 \mathrm{~km}$, populations along the northeastern coast of Mexico were isolated by distance. ${ }^{48}$ This was also observed in populations collected along the Pacific coast and the Yucatan peninsula in Mexico. ${ }^{49}$ In such cases, the dispersal of Ae. albopictus may occur primarily through flight. For this species, the maximum dispersal distance is estimated to be 800 meters. ${ }^{50}$ However, the maximum range of dispersal during adult life is usually 200 meters. ${ }^{13}$ Human movement is known to facilitate mosquito dispersal (e.g., eggs, larvae, or adults) along commercial routes and consequently attenuate genetic divergence between geographically distant populations. ${ }^{51}$ However, Ae. albopictus populations in Florida tended to become more differentiated as geographic distances separating them increased. This result confirms the small range migration ability of this species, which does not tend to disperse through human displacements. These populations had colonized this area for a sufficient time to approach equilibrium between dispersal and genetic drift, and for isolation by distance to become apparent. ${ }^{38}$ This pattern was not detected in populations collected within lower distances, as in the State of Rio de Janeiro. This could confirm that Ae. albopictus invaded the area more recently than it did in Florida, suggesting that the Brazil and United States populations were derived from independent sources. ${ }^{52}$

In the Americas, Ae. albopicus populations are still arriving from different geographic regions. The distinction between the North and the South American populations was based on egg diapause and photoperiod sensitivity. Our findings showed that Ae. albopictus from these areas were not differentiated with respect to vector competence for dengue and yellow fever viruses. Based on these findings, Ae. albopictus populations are still evolving, as is their vector competence. Since Ae. albopictus shows a relatively high susceptibility to dengue type 2 virus and a high capacity to ensure vertical transmission, ${ }^{53}$ we can assume that the present expansion of this species is a disturbing threat to dengue control in Brazil.

When Ae. albopictus and Ae. aegypti were sampled together in the same Brazilian site, we conducted experimental infection assays simultaneously with $\mathrm{F}_{1}$ females of both species for yellow fever virus. Infection rates for Ae. aegypti have been previously reported, ${ }^{31}$ and those for Ae. albopictus are shown in Table 3. Samples of Ae. albopictus from four of seven localities were more susceptible to yellow fever virus than those of Ae. aegypti: SAL (18.4\% versus $6.3 \%$, respec- 
tively), MOQ (16.6\% versus $7.6 \%)$, CSO (13.5\% versus $0.9 \%)$, and TIN (14.2\% versus $4.9 \%)$. The highest infection rate for yellow fever virus in Ae. albopictus from Brazil $(30.9 \%)$ was found in RGS (Table 3), which is located in the transition area of sylvatic yellow fever (Figure 1), where monkeys were found harboring the virus in 2001. In addition, $A e$. albopictus is widespread and often more abundant than $A e$. aegypti in the western regions of southeastern and southern Brazilian states, such as in Minas Gerais, which is close to foci of sylvatic yellow fever and where human yellow fever outbreaks have been recently reported (Brazilian Ministry of Health, unpublished data). Although less susceptible to yellow fever virus than several Ae. aegypti samples tested from Brazil, ${ }^{31} A$ e. albopictus may continue to colonize and become more abundant in rural areas and in the forest fringe in endemic and transition areas for sylvatic yellow fever, thus becoming a real problem since it could become the link between the jungle and urban cycles of yellow fever.

Received October 14, 2002. Accepted for publication March 10, 2003.

Acknowledgments: We are grateful to Pedro M. Silva, Fernanda L. P. da Silva, Allan M. Silva, Adão Pereira, Valdecir Nunes, Denilson Santos, Wellington C. Silva, Paulo J. Leite, José Reinaldo Moreira, Uranius Assumpção, Manoel Araújo, Silvia Ahid, Helder Resende, Claucio de Moraes, Nildimar Honório, Peter Armbruster, Bill Hawley, Alan Wheeler, Mike Wamack, and Marieta Braks for providing mosquito samples; Laurence Mousson, Nadia Monnier, and Catherine Thouvenot for technical assistance; and Heloisa Dinis for preparing the maps. We express our sincere appreciation to Phil Lounibos for his help in improving the manuscript.

Financial support: This work was supported by the Pasteur Institute in Paris, Fundação Oswaldo Cruz (PAPES II), the Brazilian Council of Research (CNPq), U.S. National Institute of Health grant R01 AI-44793, and L. P. Lounibos (Principal Investigator).

Authors' addresses: Ricardo Lourenço de Oliveira and Ana Maria Bispo de Filippis, Laboratórios de Transmissores de Hematozoários e de Flavivírus, Instituto Oswaldo Cruz, Fiocruz, Av. Brasil 4365, 21045-900, Rio de Janeiro, RJ, Brazil. Marie Vazeille and Anna-Bella Failloux, Unité d'Ecologie des Systèmes Vectoriels, Institut Pasteur, 25 Rue du Docteur Roux, 75724 Paris Cedex 15, France, Telephone: 33-1-40-61-36-17, Fax: 33-1-40-61-30-89, E-mail: afaillou@pasteur.fr

\section{REFERENCES}

1. Smith CEG, 1956. The history of dengue in tropical Asia and its probable relationship to the mosquito Aedes aegypti. J Trop Med Hyg 59: 243-252.

2. Rai KS, 1991. Aedes albopictus in the Americas. Annu Rev Entomol 36: 459-484.

3. Sprenger D, Wuithiranyagool T, 1986. The discovery and distribution of Aedes albopictus in Harris County, Texas. $\mathrm{J} \mathrm{Am}$ Mosq Control Assoc 2: 217-219.

4. Hawley WA, Reiter P, Copeland RS, Pumpuni CB, Craig GB Jr, 1987. Aedes albopictus in North America: probable introduction in used tires from northern Asia. Science 236: 1114-1116.

5. Consoli RAGB, Lourenço-de-Oliveira R, 1994. Principais Mosquitos de Importância Sanitária no Brasil. Rio de Janeiro: Fiocruz.

6. Nasci RS, 1995. Control of Aedes albopictus from the perspective of North America. Parasitologia 37: 123-127.

7. Mattingly PF, 1957. Genetical aspects of the Aedes aegypti problem. I. Taxonomy and bionomics. Ann Trop Med Parasitol 51: 392-408.

8. Lounibos LP, 2002. Invasion by insect vectors of human diseases. Annu Rev Entomol 47: 233-266.

9. O'Meara GF, Evans LF Jr, Gettman AD, Cuda JP, 1995. Spread of Aedes albopictus and decline of Ae. aegypti (Diptera: Culicidae) in Florida. J Med Entomol 32: 554-562.
10. Barrera R, 1996. Competition and resistance to starvation in larvae of container-inhabiting Aedes mosquitoes. Ecol Entomol 21: $117-127$.

11. Lounibos LP, Escher RL, Nishimura N, Juliano SA, 1997. Longterm dynamics of a predator used for biological control and decoupling from mosquito prey in a subtropical treehole ecosystem. Oecologia 111: 189-200.

12. Rudnick A, 1965. Studies of the ecology of dengue in Malaysia: a preliminary report. J Med Entomol 2: 203-208.

13. Hawley WA, 1988. The biology of Aedes albopictus. J Am Mosq Control Assoc 4 (Suppl): 1-39.

14. Knudsen AB, 1983. Aedes aegypti and dengue in the Caribbean. Mosq News 43: 269-275.

15. Brès PLJ, 1986. A century of progress in combating yellow fever. Bull Worls Health Organ 64: 775-786.

16. Robertson SE, Hull BP, Tomori O, Bele O, LeDuc JW, Esteves K, 1996. Yellow fever: a decade of reemergence. JAMA 276: $1157-1162$.

17. Pinheiro FP, Corber SJ, 1997. Global situation of dengue and dengue haemorrhagic fever, and its emergence in the Americas. World Health Stat Q 50: 161-169.

18. Gubler DJ, Clark GG, 1995. Dengue/dengue hemorrhagic fever. The emergence of a global health problem. Emerg Infect Dis 1: $55-57$.

19. van der Stuyft P, Gianella A, Pirard M, Cespedes J, Lora J, Peredo C, Pelegrino JL, Vorndam V, Boelaert M, 1999. Urbanization of yellow fever in Santa Cruz, Bolivia. Lancet 353: 1558-1562.

20. Prata A, 2000. Yellow fever. Mem Inst Oswaldo Cruz 95 (Suppl I): $183-187$.

21. Guzman MG, Kouri GP, Bravo J, Soler M, Vazquez S, Santos M, Villaescusa R, Basanta P, Indan G, Ballester JM, 1984. Dengue haemorrhagic fever in Cuba. II Clinical investigations. Trans $R$ Soc Trop Med Hyg 78: 239-241.

22. Gubler DJ, 2002. Epidemic dengue/dengue hemorrhagic fever as a public health, social and economic problem in the 21st century. Trends Microbiol 10: 100-103.

23. Shroyer DA, 1986. Aedes albopictus and arboviruses: a concise review of the literature. J Am Mosq Control Assoc 2: 424-428.

24. Ibanez-Bernal S, Briseno B, Mutebi JP, Argot E, Rodriguez G, Martinez-Campos C, Paz R, De la Fuente-San Roman P, Tapia-Conyer R, Flisser A, 1997. First record in America of Aedes albopictus naturally infected with dengue virus during the 1995 outbreak at Reynosa, Mexico. Med Vet Entomol 11: 305-309.

25. Serufo JC, Montes de Oca H, Tavares VA, Souza AM, Rosa RV, Jamal MC, Lemos JR, Oliveira MA, Noguiera RMR, Schatzmayr HG, 1993. Isolation of dengue virus type 1 from larvae of Aedes albopictus in Campos Altos city, state of Minas Gerais, Brazil. Mem Inst Oswaldo Cruz 88: 503-504.

26. Rudnick A, Marchette NJ, Garcia R, 1967. Possible jungle dengue-recent studies and hypotheses. Jpn J Med Sci Biol 20: 6974.

27. Pan American Health Organization, 1987. Control of Aedes albopictus in the Americas. Bull Pan Am Health Organ 21: 314324.

28. Mitchell CJ, Miller BR, Gubler DJ, 1987. Vector competence of Aedes albopictus from Houston, Texas, for dengue serotypes 1 to 4, yellow fever and Ross River viruses. J Am Mosq Control Assoc 3: 460-465.

29. Boromisa RD, Rai KS, Grimstad PR, 1987. Variation in the vector competence of geographic strains of Aedes albopictus for dengue 1 virus. J Am Mosq Control Assoc 3: 378-386.

30. Reiter P, Amador M, Colon N, 1991. Enhancement of the CDC ovitrap with hay infusions for daily monitoring of Aedes aegypti populations. J Am Mosq Control Assoc 7: 52-55.

31. Vazeille-Falcoz M, Mousson L, Rodhain F, Chungue E, Failloux AB, 1999. Variation in oral susceptibility to dengue type 2 virus of populations of Aedes aegypti from the islands of Tahiti and Moorea, French Polynesia. Am J Trop Med Hyg 60: 292299.

32. Lourenço de Oliveira R, Vazeille M, Bispo AM, Failloux AB, 2002. Oral susceptibility to yellow fever virus of Aedes aegypti from Brazil. Mem Inst Oswaldo Cruz 97: 437-439.

33. Kuberski TT, Rosen L, 1977. A simple technique for the detec- 
tion of dengue antigen in mosquitoes by immunofluorescence. Am J Trop Med Hyg 26: 533-537.

34. Failloux AB, Vazeille M, Rodhain F, 2003. Geographic genetic variation in populations of the dengue virus vector Aedes aegypti. J Mol Evol 55: 653-663.

35. Raymond M, Rousset F, 1995. Genepop (version 1.2): population genetics software for exact tests and ecumenicism. J Hered 86: 248-249.

36. Weir BS, Cockerham CC, 1984. Estimating F-statistics for the analysis of population structure. Evolution 38: 1358-1370.

37. Rousset F, Raymond M, 1995. Testing heterozygote excess and deficiency. Genetics 140: 1413-1419.

38. Slatkin M, 1993. Isolation by distance in equilibrium and nonequilibrium populations. Evolution 47: 264-279.

39. Ohta T, 1982. Linkage disequilibrium due to random genetic drift in finite subdivided populations. Proc Natl Acad Sci USA 79: 1940-1944.

40. Hafkin B, Kaplan JE, Reed C, Elliott LB, Fontaine R, Sather GE, Kappus K, 1982. Reintroduction of dengue fever into the continental United States. I. Dengue surveillance in Texas, 1980. Am J Trop Med Hyg 31: 1222-1228.

41. Schatzmayr HG, 2000. Dengue situation in Brazil by year 2000 . Mem Inst Oswaldo Cruz 95: 179-181.

42. Lorenz L, Beaty BJ, Aitken TH, Wallis GP, Tabachnick WJ, 1984. The effect of colonization upon Aedes aegypti susceptibility to oral infection with yellow fever virus. Am J Trop Med Hyg 33: 690-694.

43. Vazeille M, Rosen L, Mousson L, Failloux AB, 2003. Low oral receptivity for dengue type 2 viruses of Aedes albopictus from south-east Asia compared to that of Aedes aegypti. Am J Trop Med Hyg 68: 203-208.

44. Miller BR, Ballinger ME, 1988. Aedes albopictus mosquitoes introduced into Brazil: vector competence for yellow fever and dengue viruses. Trans R Soc Trop Med Hyg 82: 476-477.

45. Jupp PG, Kemp A, 2002. Laboratory vector competence experiments with yellow fever virus and five South African mosquito species including Aedes aegypti. Trans $R$ Soc Trop Med Hyg 96: 493-498.

46. Ayres CFJ, Romao TPA, Melo-Santos MAV, Furtado AF, 2002. Genetic diversity in Brazilian populations of Aedes albopictus. Mem Inst Oswaldo Cruz 97: 871-875.

47. Black WCIV, Ferrari JA, Rai KS, Sprenger D, 1988. Breeding structure of a colonizing species: Aedes albopictus (Skuse) in the United States. Heredity 60: 173-181.

48. Gorrochotagui-Escalante N, De Lourdes Munoz M, FernandezSalas I, Beaty BJ, Black WC IV, 2000. Genetic isolation by distance among Aedes aegypti populations along the northeastern coast of Mexico. Am J Trop Med Hyg 62: 200-209.

49. Gorrochotagui-Escalante N, Gomez-Machorro C, LozanoFuentes S, Fernandez-Salas I, De Lourdes Munoz M, FarfanAle JA, Garcia-Rejon J, Beaty BJ, Black WC IV, 2002. Breeding structure of Aedes aegypti populations in Mexico varies by region. Am J Trop Med Hyg 66: 213-222.

50. Honório NA, Silva WC, Leite PJ, Gonçalves JM, Lounibos LP, Lourenço-de-Oliveira R, 2002. Dispersal of Aedes aegypti and Aedes albopictus (Diptera: Culicidae) in a urban endemic dengue area in the state of Rio de Janeiro, Brazil. Mem Inst Oswaldo Cruz 98: 191-198.

51. Vazeille M, Mousson L, Rakatoarivony I, Villeret R, Rodhain F, Duchemin JB, Failloux AB, 2001. Population genetic structure and competence as a vector for dengue 2 virus of Aedes aegypti and Aedes albopictus from Madagascar. Am J Trop Med Hyg 65: 491-497.

52. Birungi J, Munstermann LE, 2002. Genetic structure of Aedes albopictus (Diptera: Culicidae) populations based on mitochondrial ND5 sequences: evidence for an independent invasion into Brazil and United States. Ann Entomol Soc Am 95: 125-132.

53. Mitchell CJ, Miller BR, 1990. Vertical transmission of dengue viruses by strains of Aedes albopictus recently introduced into Brazil. J Am Mosq Control Assoc 6: 251-253. 


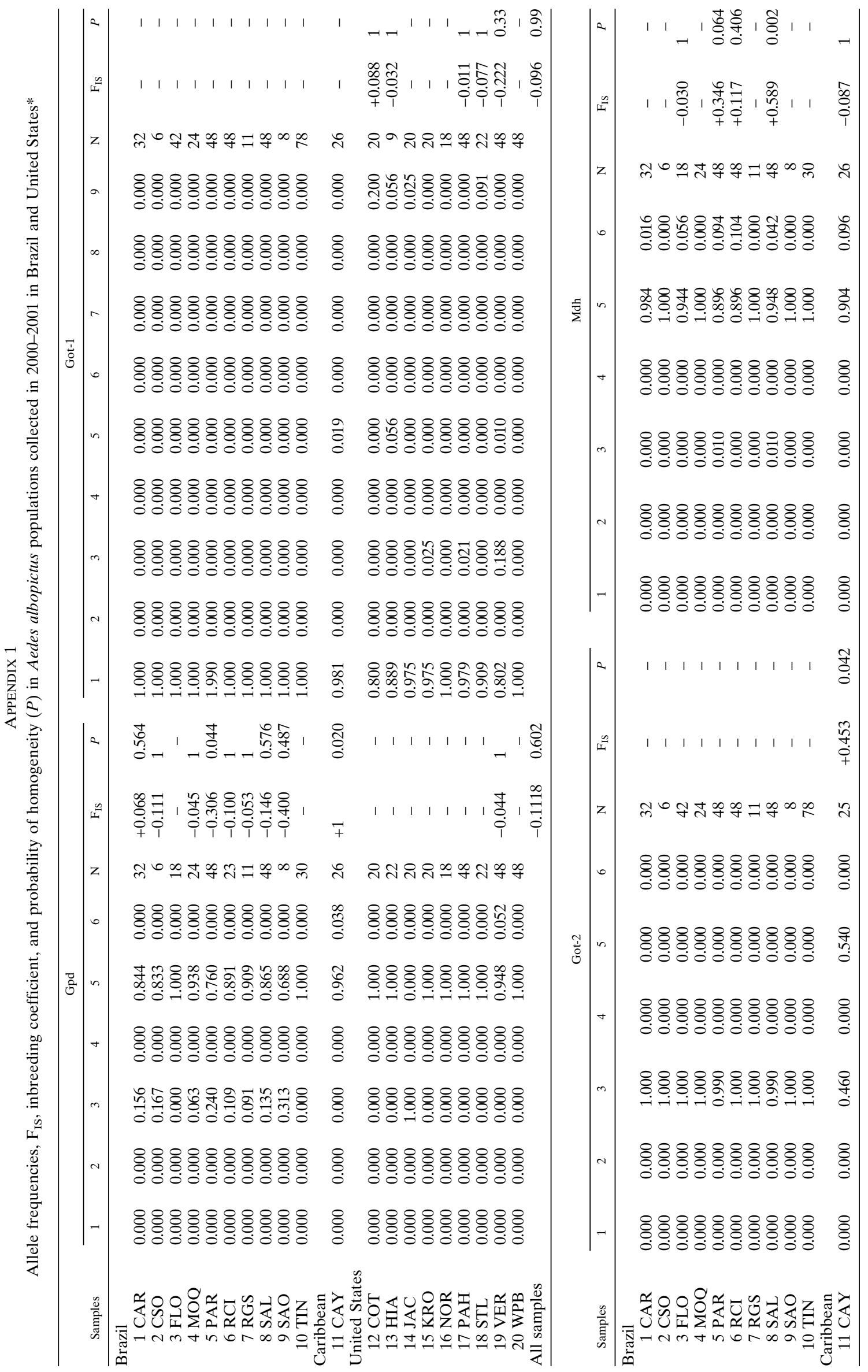




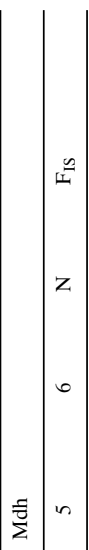

•

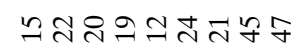

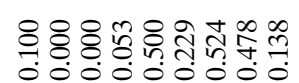

훌

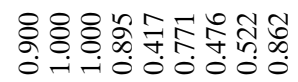

৪:

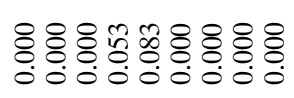

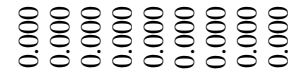

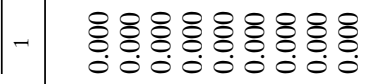

2

年

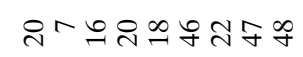

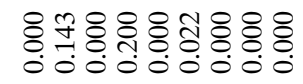

的

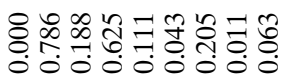

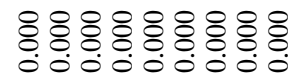

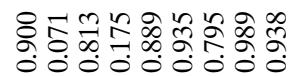

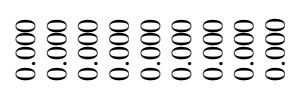

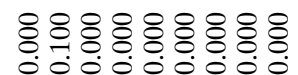

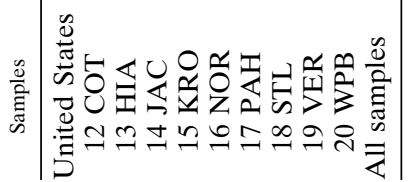

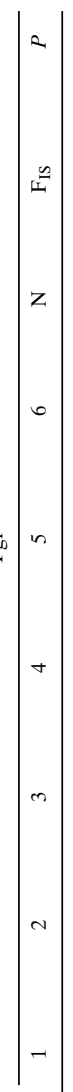

1 1 1 1 1 1 in

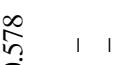

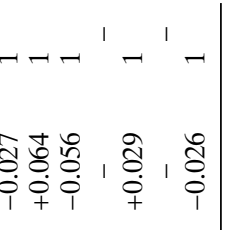

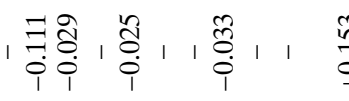

鿷 1

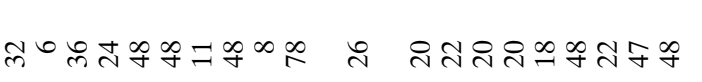

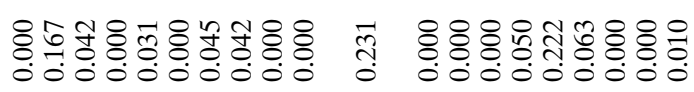

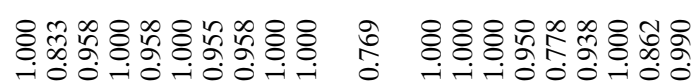

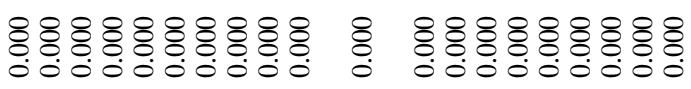

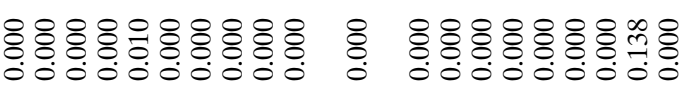

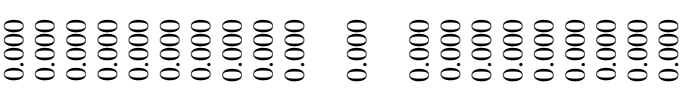

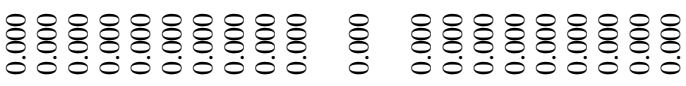

2

㝘,

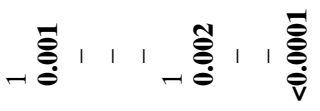

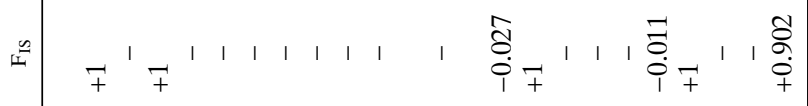

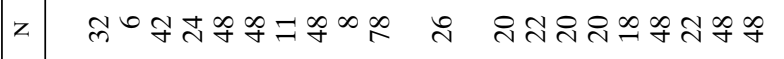

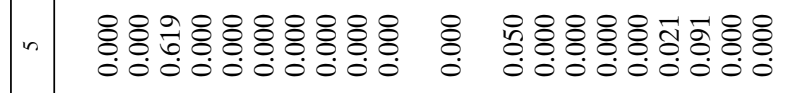

$\stackrel{0}{2}$

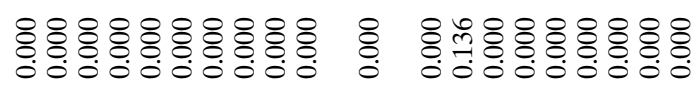

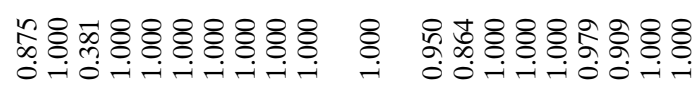

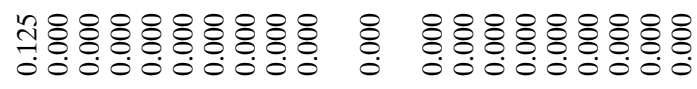

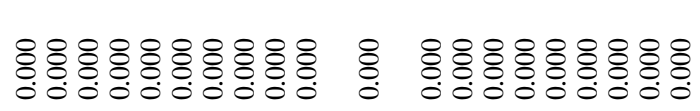

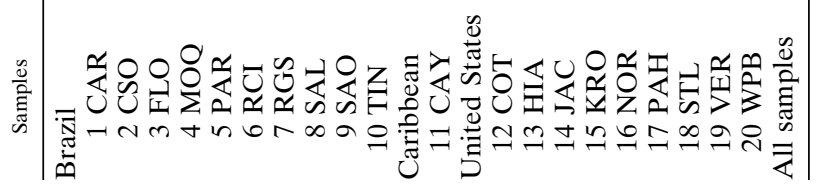




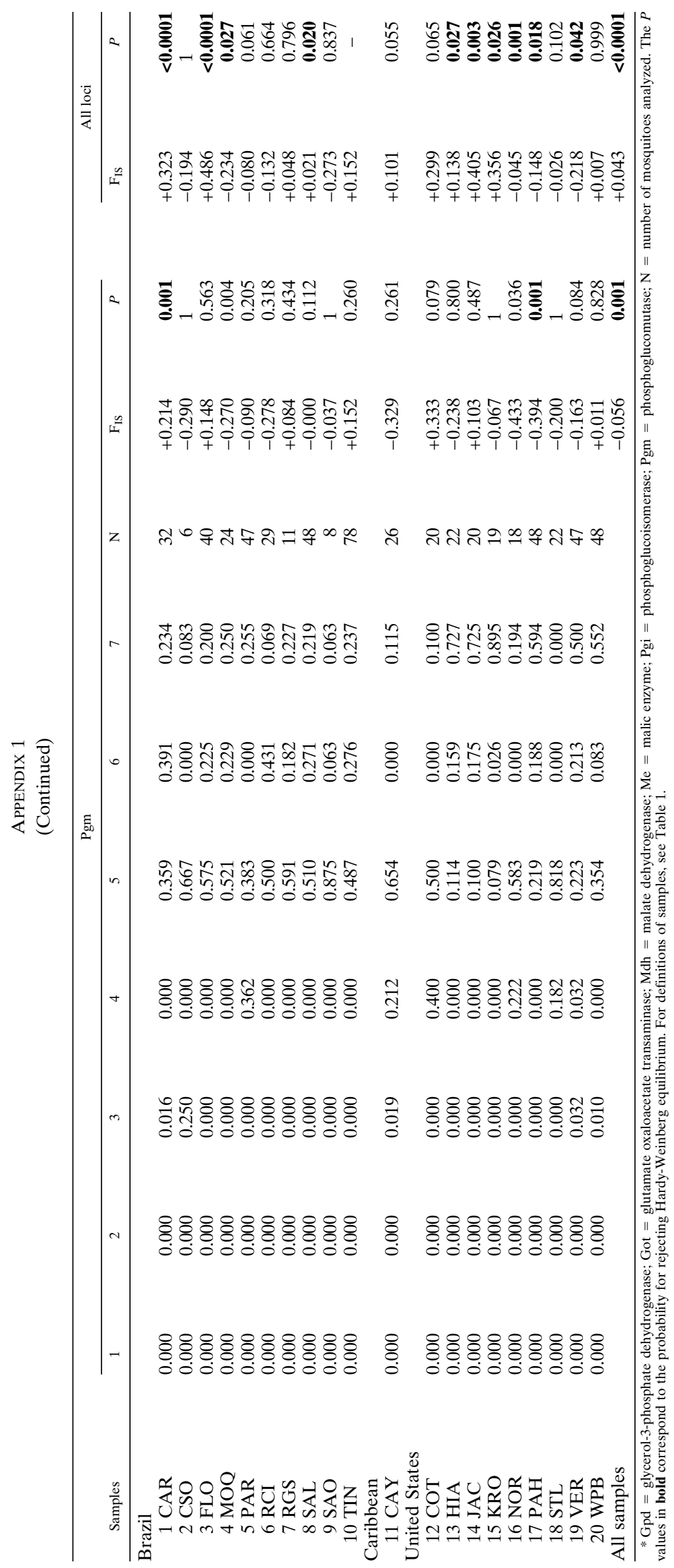

